\title{
Terapia génica en enfermedades neurodegenerativas y demencia post infarto cerebral: perspectiva de traslación
}

\author{
Johanna Gutiérrez-Vargas, Gloria Patricia Cardona-Gómez* \\ Área de Neurobiología Celular y Molecular, Grupo de Neurociencias de Antioquia, Facultad de Medicina, \\ Sede de Investigación Universitaria, Universidad de Antioquia, Medellín, Colombia \\ Artículo de posesión para el ingreso como miembro correspondiente a la \\ Academia Colombiana de Ciencias Exactas, Físicas y Naturales el 24 de noviembre de 2016
}

\begin{abstract}
Resumen
Las enfermedades cerebrovasculares se han convertido en un problema de salud mundial debido a su alta tasa de mortalidad y discapacidad. En Colombia constituyen la tercera causa de riesgo de muerte y en el mundo son la primera causa de discapacidad física y mental. Se han evaluado muchas estrategias terapéuticas en modelos experimentales y en ensayos clínicos sin buenos resultados. Algunas de las falencias de los estudios sobre tales estrategias terapéuticas son el reducido tiempo de intervención (menos de cuatro horas y media), así como el poco tiempo de protección y la falta de seguimiento de la terapia, lo cual genera secuelas a largo plazo en los pacientes. La terapia génica ha demostrado ser una herramienta de gran utilidad para el tratamiento de las enfermedades neurodegenerativas; sin embargo, en el caso específico de la isquemia cerebral hay pocos estudios experimentales. En nuestras investigaciones hemos constatado el potencial de la terapia génica basada en el ARN de interferencia para prevenir y revertir la neurodegeneración y el deterioro cognitivo después de un infarto cerebral, aunque todavía deben sortearse algunas dificultades terapéuticas inherentes al sistema nervioso cerebral, así como concertar los intereses de los diversos sectores involucrados: el Gobierno, las empresas y el sector científico y académico, con el fin de incentivar la inversión y facilitar la aplicación en otras partes del país de las terapias promisorias propuestas en nuestra región para disminuir las secuelas de enfermedades crónicas no transmisibles, entre ellas la incapacidad física y mental después de un infarto cerebral. (C) 2017. Acad. Colomb. Cienc. Ex. Fis. Nat.
\end{abstract}

Palabras claves: Infarto cerebral; Enfermedades neurodegenerativas; Demencia; Terapia génica; ARN de Interferencia; Medicina de traslación.

\section{Gene therapy in neurodegeneration and dementia post-stroke}

\begin{abstract}
Cerebrovascular disease has become a worldwide health problem due to its high mortality and disability rate. It is the third leading cause of death risk in our country and the first cause of physical and mental disability in the world. Many therapeutic strategies have been evaluated both in experimental models and in clinical trials without success. One of the major shortcomings of these therapeutic studies is the limitation in the intervention time (less than four and a half hours) and the short time of protection or follow-up of the therapy, which generates long-term sequelae in the patients. Gene therapy has been shown to be a very useful tool for the treatment of neurodegenerative diseases; however, experimental studies are few, specifically in cerebral ischemia. Our research has demonstrated the potential benefit of RNA interference based gene therapy to prevent and reverse neurodegenerative effects and cognitive impairment following a stroke. However, therapeutic difficulties inherent to the cerebral nervous system should be overcome, and the interests of government, business and scientific and academic sectors should be coordinated to procure investment and to facilitate the translation of promising therapies proposed from our region aimed at reducing the sequelae of chronic non-communicable diseases, including physical and mental disability after a stroke. (C) 2017. Acad. Colomb. Cienc. Ex. Fis. Nat.
\end{abstract}

Key words: Stroke; Neurodegeneration; Cognitive impairment; Dementia; Gene therapy; RNA interference; Translational medicine.

\footnotetext{
*Correspondencia:

Gloria Patricia Cardona-Gómez, patricia.cardonag@udea.edu.co; Recibido: 19 de noviembre de 2016; Aceptado: 7 de marzo de 2017
} 


\section{Isquemia cerebral}

Accidente cerebrovascular: prevalencia y clasificación. Los accidentes cerebrovasculares (ACV) son la segunda causa de muerte en el mundo y la primera causa de discapacidad en los adultos (Bejot, et al., 2007). Según la Organización Mundial de la Salud (OMS), cada año 15 millones de personas sufren un accidente cerebrovascular y de ellos mueren 5,5 (10\% del total de defunciones) de ellos, otros 5 quedan con alguna incapacidad permanente (CDC, 2008). Se estima que en 30 años y hasta el 2020 se habrían perdido 61 millones de días de vida sana a causa del ACV (CDC, 2008).

Debido al envejecimiento de muchas poblaciones en el mundo, las proyecciones para el año 2020 parecen indicar que el ACV seguirá siendo la segunda causa de muerte tanto en los países desarrollados como en aquellos en vía de desarrollo (Bejot, et al., 2007). En términos de discapacidad, los ACV estarán entre los cinco principales contribuyentes, lo cual implica enormes cargas económicas para los sistemas de salud debido a los recursos que serán necesarios para atender a los pacientes en fase aguda, al igual que ofrecer a los sobrevivientes los cuidados a largo plazo (CDC, 2008).

Los dos principales mecanismos que causan daño cerebral en el ACV son, la isquemia y la hemorragia (Assarzadegan,

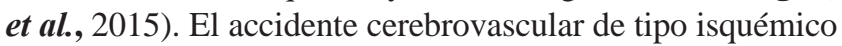
que representa alrededor del 80\% de los ACV, es debido a disminución o ausencia de circulación sanguínea hacia el cerebro. Al presentarse la disminución y cesar la oxigenación neuronal, se produce una disminución del metabolismo de estas células debido a la carencia de los sustratos necesarios. Los efectos de la isquemia son rápidos ya que el cerebro no almacena la glucosa necesaria como sustrato energético principal, lo que le hace incapaz de realizar el metabolismo anaeróbico (Goldstein, et al., 2011).

La presencia de un trombo o émbolo puede generar la oclusión de una arteria cerebral, lo que conduce al desarrollo de un proceso isquémico en el territorio vascular afectado. Los mecanismos de compromiso y daño neuronal son causados por la hipoxia o la anoxia celular (Amlie-Lefond, et al., 2009).

Patofisiología de la isquemia cerebral. Al obstruirse los vasos sanguíneos que suministran sangre a la totalidad o a la mayor parte del cerebro, la lesión se llama isquemia global, la que suele ocurrir durante un ataque cardíaco o una hipotensión sistémica aguda. Sin embargo, si sólo se produce la oclusión de los vasos que suministran sangre a un área determinada del cerebro, se genera una isquemia focal (Durukan, Tatlisumak, 2007; Dirnagl, Ladecola, Moskowitz, 1999). Aproximadamente el 80\% de los casos de isquemia focal son resultado de la oclusión de la arteria cerebral media (ACM) (Durukan, et al., 2007).

En la isquemia focal, la región que sufre el más grave grado de hipoperfusión sanguínea progresa rápidamente hacia un daño irreversible debido a una muerte necrótica, que representa el núcleo isquémico (Figura 1). Esta zona presenta bajo flujo sanguíneo cerebral $(<10 \%$ del valor basal) y daño irreversible del metabolismo energético. El tejido hipoperfundido restante que rodea el núcleo isquémico presenta un desequilibrio en los mecanismos de la autorregulación del flujo sanguíneo y se lo conoce como la zona de penumbra (Figura 1) (Moustafa, Baron, 2008). En esta región, las neuronas muestran alteraciones funcionales, si bien conservan una actividad metabólica mínima que preserva la integridad estructural durante un período de tiempo más largo, el que conduce a un patrón de muerte apoptótica (Moskowitz, Lo, Iadecola, 2010). La penumbra es potencialmente recuperable y representa un objetivo clave para la intervención terapéutica en la isquemia cerebral. Este período crítico de viabilidad durante el cual este volumen de tejido cerebral está en riesgo, es conocido como la "ventana de oportunidad", ya que el déficit creado por la isquemia puede ser parcial o totalmente revertido dentro de un período crítico de dos a cuatro horas y media. Sin embargo, a menos que se mejore la perfusión, las células de la zona de penumbra están en riesgo de morir en unas pocas horas por necrosis (Lo, 2008).

A nivel molecular, el desarrollo de la lesión neuronal isquémica está dada en gran medida por un incremento en la liberación al espacio sináptico de neurotransmisores de tipo excitatorio, principalmente de glutamato. Este proceso llamado "excitotoxicidad” es una respuesta canónica como consecuencia de la falla de la bomba de iones y déficit energético, así como también por la insuficiencia de mecanismos de retoma del neurotransmisor por parte de células astrocíticas (Choi, Rothman, 1990).

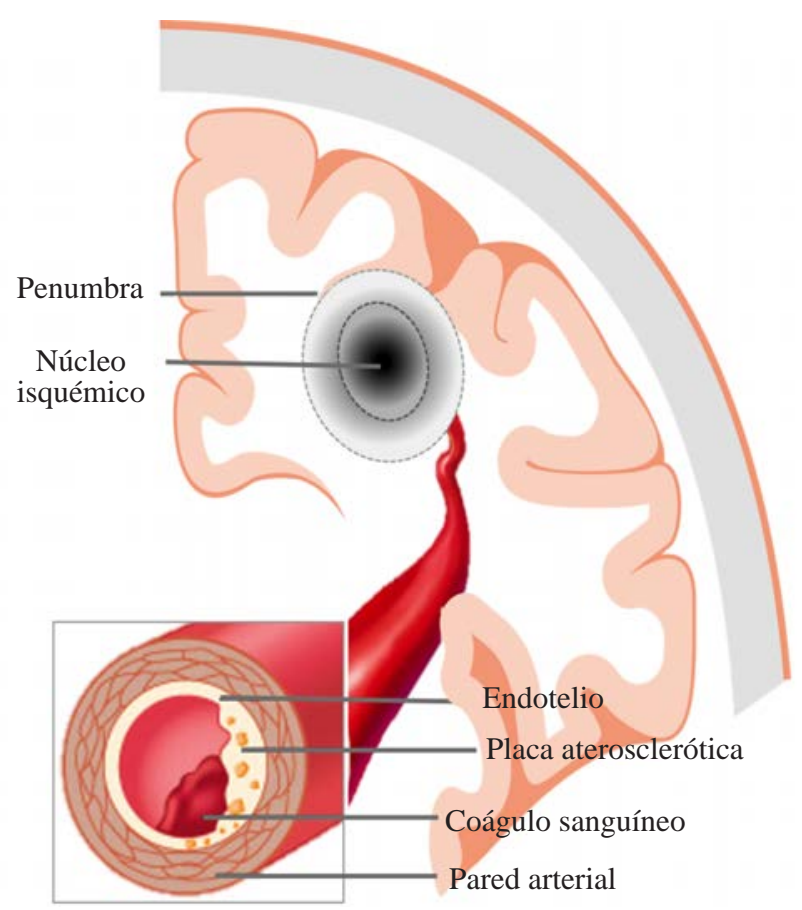

Figura 1. El infarto generado tras una isquemia focal. Éste se divide principalmente en el núcleo isquémico y la zona de penumbra; generalmente se presenta por la formación de una placa aterosclerótica o un coágulo sanguíneo en el territorio de la ACM. 
La sobrecarga de glutamato conduce a la estimulación prolongada de receptores ionotrópicos de glutamato de tipo AMPA (ácido $\alpha$-amino-3-hidroxi-5-metil-4- isoxazolepropionico) y de receptores NMDA (ácido N-metil-D-aspártico), los que aumentan drásticamente el influjo de calcio $(\mathrm{Ca} 2+)$, sodio $(\mathrm{Na}+)$, potasio $(\mathrm{K}+)$ y agua en las neuronas. La acumulación excesiva de iones y la desregulación simultánea de varias vías de señalización mediadas por proteasas, lipasas, y nucleasas, llevan a la alteración de la función neuronal y conducen a la muerte celular (Won, Kim, Gwag, 2002).

Discapacidades a corto y largo término luego de una isquemia cerebral. Anualmente cerca de 15 millones de personas en todo el mundo sufren una isquemia cerebral y cerca del 30\% de éstos experimentan discapacidades residuales significativas (CDC, 2008), lo que hace que esta enfermedad sea una de las principales causas de discapacidad en el mundo, lo que ha sido conceptualizado por la Organización Mundial de la Salud (OMS) como una restricción resultante de la falta de capacidad para llevar a cabo una actividad considerada como normal para el hombre (OMS, 2016).

Esta discapacidad es doble y se clasifica como motora y de locomoción, de comunicación, emocional, visual, auditiva y cognitiva. El conjunto de las discapacidades físicas en los sobrevivientes de un infarto cerebral es simultáneo o secundario a la enfermedad, temporal o permanentemente, el cual causa daños en las actividades de la vida diaria como alimentarse, vestirse, cuidar de la higiene personal, uso de transporte, entre otros (Dobkin, Dorsch, 2013). Horn, et al., 2003 consideran que la hemiparesia o hemiplejia, es la principal discapacidad grave de la sociedad actual. El ajuste a esta discapacidad física después de un ACV es un proceso de colaboración entre el paciente, la familia y los profesionales de la salud. Esta colaboración no se limita al ambiente hospitalario ya que continúa durante todo el curso de la enfermedad.

Sin embargo, el deterioro cognitivo posterior al evento isquémico casi siempre es ignorado en los pacientes, debido precisamente a la severidad de la discapacidad física que presenta la mayoría de ellos. Estos pacientes presentan un grado de repercusión que puede ser dividido en deterioro cognitivo leve y demencia (Sun, Tan, Yu, 2014). Según Nys, et al., 2005 una alta proporción de sobrevivientes al infarto cerebral tienen deterioro cognitivo luego de los 3 meses y, en ocasiones, la demencia solo es detectada luego de varios años de ocurrida la lesión. Aunque la prevalencia del deterioro cognitivo post-isquemia es alta según los datos actuales, todavía hay pruebas que demuestran que los actuales criterios de valoración pueden subestimar la frecuencia del deterioro cognitivo en los sobrevivientes. La prevalencia del deterioro cognitivo varía entre el $20 \%$ al $80 \%$, proporción que se define según la casuística de cada país, los criterios de diagnóstico y el tiempo post-lesión (Sun, 2014). De acuerdo con la OMS en Sur América los afectados por ACV suelen ser cinco o seis afectados por cada 1000 habitantes, siendo Brasil el más alto con 11 por cada 10000 (Lavados, et al., 2007). Sin embargo, no hay cifras concretas de cuantas personas sufren problemas cognitivos, debido a los pocos estudios realizados y a la falta de conciencia de que el deterioro cognitivo se constituye como una creciente problemática de salud en los pacientes que sobreviven luego de una isquemia cerebral. No obstante, se estima que en América Latina la gente con demencia incrementará en un 368\% para el 2050, más alto que en EEUU y Europa (WHO, 2015, ADI/BUPA, 2013); de esta cifra, una parte importante representa la consecuencia de enfermedades cerebrovasculares, como consecuencia del sedentarismo y una ingesta alta en grasas y azúcares.

Hay pruebas que sugieren que el deterioro del hipocampo está asociado con la demencia post-isquemia. Un estudio realizado por Szabo, et al., 2009 sugiere que la lesión en el hipocampo podría conducir al deterioro persistente de la memoria, considerado como la consecuencia habitual de la oclusión de la arteria cerebral posterior. En recientes estudios, Gemmell, et al., 2012, 2014, al analizar el volumen del hipocampo en muestras post-mortem de pacientes que presentaron demencia, sugirieron que el volumen del cerebro alterado era entre el 10-20\% en las regiones de CA1 y CA2 y del 20\% en las regiones de CA3 y CA4 del hipocampo. Sin embargo, son aún inciertos el o los mecanismos de la lesión post-isquémica en el hipocampo y si ellos se relacionan con el deterioro cognitivo. Algunos estudios, incluidos los nuestros (Castro-Alvarez, et al., 2011, 2014a), han demostrado que la hiperfosforilación de Tau es considerada un marcador de neurodegeneración posterior a la isquemia cerebral y está estrechamente correlacionado con el desorden cognitivo y la demencia (Pluta, et al., 2011)

Hasta el momento no hay ningún tratamiento eficaz para tratar el deterioro cognitivo post-isquemia. Algunos de los fármacos usados para el tratamiento de la demencia en la enfermedad de Alzheimer (AD), han demostrado algunos efectos positivos en la discapacidad cognitiva postisquemia (Brainin, et al., 2015). Por ejemplo, agentes antiinflamatorios, moduladores de barrera hematoencefálica, antagonista de la endotelina, flavonoides, agentes inmunosupresores, antidepresivos, agentes neurotróficos entre otros. Sin embargo, pese a que ninguno de ellos se ha establecido como tratamiento efectivo, se han definido unos objetivos claves para la prevención del deterioro cognitivo, los que se centran en el tratamiento agudo (para limitar el daño desde el inicio de la lesión y prevenir la recurrencia temprana) y en la prevención de la recurrencia a largo plazo.

Terapia de neuroprotección en isquemia cerebral: futuras perspectivas en medicina translacional. Durante las últimas dos décadas, los agentes neuroprotectores diseñados para bloquear la muerte celular han sido investigados en modelos animales de isquemia cerebral. Se han encontrado numerosos fármacos que reducen el tamaño del infarto en modelos de isquemia en roedores, conejos y primates. Sin embargo, la neuroprotección como estrategia para el 
tratamiento del ictus, eficaz en modelos experimentales, ha fracasado en estudios clínicos en fase III (Cheng, Al-Khoury, Zivin, 2004). Sumado a lo anterior, la única terapia vigente para el infarto cerebral está limitada al tratamiento con el factor activador del plasminógeno tisular recombinante (rt-PA), que, aunque mejora el pronóstico funcional, sólo se emplea en menos de un 3\% de pacientes (Castillo, et al., 2003).

Varias dificultades se han identificado a la hora de establecer una terapia eficaz que limite las devastadoras consecuencias del reducido flujo sanguíneo en la zona de penumbra y prevenga los insultos secundarios inducidos por la reperfusión (Moskowitz, et al., 2010). Por ejemplo, un enfoque hacia un único evento de la cascada isquémica podría no ser suficiente para disminuir las consecuencias de una condición multifactorial como lo es la isquemia cerebral (Chavez, et al., 2009). En este escenario, tratamientos individuales específicos efectivos a cierto tiempo, bajo un rango dado de condiciones fisiológicas, pueden ser ineficaces. Sin embargo, si lo utilizamos como contexto de acción terapéutica, eventos troncales en el fenómeno de isquemia/re-perfusión como la excitoxicidad por glutamato y evitamos su onda de propagación por la circuitería neural local, se podrían bloquear varios fenómenos fisiopatológicos asociados, como la activación de calpainas, caspasas, actividad enzimática, disregulación de sustratos, activación de rutas de muerte, despolimerización del citoesqueleto de microtúbulos y de actina, entre otros.

Por ejemplo, el uso de las estatinas ha mostrado tener efectos benéficos luego de un evento isquémico (GutiérrezVargas, Múnera, Cardona-Gómez, 2015). Las estatinas, inhibidores competitivos de la 3-hidroxi-3-metilglutaril coenzima A (HMG-CoA) reductasa, son fármacos reductores del colesterol y con múltiples efectos pleiotrópicos en isquemia cerebral, tales la como mejora de la función endotelial, tienen potencial efecto anti-oxidante, antitrombótico y anti-inflamatorio, entre otros (Goldstein, et al., 2011). Nuestros estudios han mostrado que la terapia postisquemia con estatinas recupera el déficit neurológico y el de memoria, así como el aprendizaje, a la par que activa vías de supervivencia y plasticidad sináptica asociadas a la recuperación neuronal. Estos fármacos también regulan los receptores de glutamato de tipo NMDA, los cuales juegan un papel crucial en la excitotoxicidad por glutamato, y por ende, estos fármacos regulan de manera troncal eventos primarios que generan la lesión.

Otra alternativa que se ha propuesto, ha sido la combinación de dos o más agentes potenciales neuroprotectores, cada uno con un objetivo diferente con respecto a la cascada neurodegenerativa, lográndose así efectos sinérgicos en la protección de la lesión isquémica. Por ejemplo, se han hecho estudios en modelos experimentales donde las estatinas son administradas en combinación con el rt-PA con obtención de grandes beneficios en cuanto a la recuperación post-infarto (Zhang, Zhang, Chopp, 2012). De acuerdo con lo anterior, el o los agentes neuroprotectores ideales deberían demostrar eficacia el evaluar estados neurológicos, con soporte histopatológico, y determinación del volumen de infarto y teniendo en consideración estudios de biodistribución, bioequivalencia, farmacocinética y farmacodinamia, así como análisis de seguridad y toxicidad que demuestren el mínimo de efectos adversos (Cheng, et al., 2004).

La gran discrepancia existente entre los resultados obtenidos en el laboratorio y los ensayos clínicos hace que se dificulte la translación de muchas terapias ensayadas con éxito en modelos experimentales, (Cheng, et al., 2004). En los modelos de accidente cerebrovascular, los investigadores suelen elegir animales jóvenes y sanos. Sin embargo, los pacientes con infarto cerebral suelen ser de edad avanzada y sufren de múltiples enfermedades crónicas, tales como la arteriosclerosis, hipertensión, diabetes e hiperlipidemia (Demchuk, Buchan, 2000).

Otro impedimento, es que la mayor parte de los estudios en modelos de isquemia se realizan a corto plazo, basándose en el hecho de que los tratamientos iniciados en las primeras horas del establecimiento de los síntomas tienen una mayor probabilidad de convertirse en una terapéutica efectiva. Sin embargo, muchos agentes terapéuticos considerados efectivos en estudios de la fase aguda han resultado ser indistinguibles de su vehículo en la etapa sub aguda o crónica. Ello es debido, en parte, a la falta de determinación de la ventana de acción terapéutica del tratamiento, al hecho de tener en cuenta que luego de un evento isquémico se generan cambios fisiopatológicos diferentes que varían con respecto al tiempo post-lesión, por ejemplo: a pocas horas de la muerte celular, luego de varios días, el proceso inflamatorio, la astrogliosis y la microgliosis; y posterior a ello, luego de días y semanas, aparece la pérdida de espinas y dendritas que perduran a largo término post-infarto y desencadenan así pérdida de funciones (Posada-Duque, Barreto, Cardona-Gomez, 2014). Aunque en la mayoría de los ensayos clínicos 90 días es el tiempo elegido como criterio de valoración principal para los estudios de neuroprotección, pudiera resultar muy apropiado prolongar el tiempo de seguimiento de la evolución clínica del paciente (Cheng, et al., 2004) para determinar posibles complicaciones médicas por tratamientos a largo plazo o, por el contrario, para demostrar la eficacia del agente neuroprotector al evitar la secuelas a largo término post-isquemia, y de este modo, ir construyendo criterios para ampliar el uso y los beneficios de la terapia, o generar alertas y especificar protocolos de atención al paciente con infarto cerebral.

De acuerdo con todo lo anterior, se espera entonces que los estudios de neuroprotección en modelos experimentales se ajusten a las condiciones reales que se presentan en los pacientes que sufren un episodio de isquemia, como factores de morbilidad, edad, tiempo post-infarto; y, además, que se cuente con las herramientas metodológicas más apropiadas para abordar la problemática desde el aspecto paraclínico, histopatológico, bioquímico-molecular y la concomitante evaluación funcional motora, cognitiva y emocional, con perspectiva de traslación. 


\section{Terapia génica en infarto cerebral ventajas y limitaciones}

Generalidades de la terapia génica. La terapia génica es un tratamiento alternativo a los abordajes farmacológicos, quirúrgicos y de índole convencional que se están desarrollando tanto en investigación básica como clínica. Principalmente, consiste en la modificación específica de un gen para prevenir, o remediar, una condición patológica para el organismo. Esta técnica se basa en la interferencia, corrección o sustitución del gen defectuoso dentro de las células que expresan la patología por el gen normal y su correcta proteína funcional de manera de retardar, estabilizar o revertir el curso de la enfermedad (Grimm, Kay, 2007).

De acuerdo con el tipo de trastorno, la terapia génica se realiza a través de alguno de los siguientes abordajes (Fillat, 2004):

Adición génica: consiste en introducir una copia correcta del gen funcional para que éste produzca - en cantidades adecuadas - la proteína correspondiente en el tejido a tratar. Es el procedimiento más utilizado.

Corrección génica: busca corregir el gen alterado sustituyéndolo por el gen correcto mediante recombinación homóloga, aunque por el momento este método es poco eficiente. En su lugar, es posible intercambiar un nucleótido específico mutado, lo que resulta útil para tratar enfermedades con mutaciones puntuales.

Supresión génica: consiste en reducir la expresión de un determinado gen, lo cual se logra mediante el uso de RNA de interferencia (shRNA) que induce la degradación o silenciamiento del RNA mensajero (mRNA) blanco.

El mecanismo del RNA de interferencia puede inducirse mediante la presencia de shRNA codificados directamente desde el núcleo o bien por shRNA generados a partir de un vector de $\mathrm{ADN}$ que contiene un promotor específico de tejido y que sintetiza constitutivamente a estos shRNA. Cualquiera que sea su origen, los shRNA presentan algunas características en común: contienen de 21 a 23 nucleótidos de longitud y son dúplex con morfología tipo pasador o tallo-asa (hairpin); contienen un extremo 5' fosforilado y un extremo $3^{\prime}$ con dos nucleótidos que sobresalen de la estructura tipo pasador. Estas características los hacen específicos para que puedan ser reconocidos por el complejo de silenciamiento inducido por RNA (RISC, del inglés RNAinduced silencing complex). RISC es una nucleasa efectora multicomponente que reconoce al shRNA dúplex $\mathrm{y}$, como presenta actividad helicasa, lo que hace es deshebrar al shRNA dúplex, con el ingreso de ATP, a través de la proteína catalítica denominada Argonauta. De esta forma RISC junto con el shRNA de una sola hebra, detecta al mRNA blanco al reconocerlo por apareamiento de bases altamente específica (Boudreau, Rodriguez-Lebron, Davidson, 2011).

El silenciamiento génico post-transcripcional (proceso completamente citoplasmático) es el resultado del corte endonucleolítico del mRNA blanco mediante una enzima con actividad de RNasa $\mathrm{H}$, conocida como slicer, la cual tiene un dominio denominado PIWI que interviene en el silenciamiento génico (Parker, Roe, Barford, 2004). El corte ocurre sólo en la región homóloga entre el mRNA y el shRNA (Juliano, et al., 2005). Además, RISC tiene la capacidad de degradar completamente al mRNA. Adicionalmente, RISC posee actividad de polimerasa, de modo que emplea los mismos shRNA como molde para hacer múltiples copias y amplificar la señal de silenciamiento (Boudreau, et al., 2011).

En el marco de la terapia basada en la interferencia génica, se ha ensayado la administración de shRNA en modelos experimentales y ensayos clínicos mediante diversos vehículos entre los que se cuentan con vectores virales, liposomas y nanopartículas (Li, Huang, 2000; Kay, Glorioso, Naldini, 2001). Los vectores virales poseen una mayor eficacia en la transferencia de ADN-RNA, pero son más propensos a generar una respuesta inmune no deseada en el paciente. La integración del gen de interés al vector requiere de la eliminación de los genes que le confieren su virulencia incorporándose en su lugar la secuencia deseada. Dentro de los vectores virales, los más utilizados son los retrovirus, adenovirus, lentivirus, virus de herpes simple y virus adeno asociados (Kay, Glorioso, Naldini, 2001; CLINIGENE). Estos últimos son los que presentan menos respuesta inflamatoria. Los vectores no virales son menos efectivos en la transferencia, pero más seguros y más sencillos de elaborar, caracterizar y manipular (Boudreau, et al., 2011).

Terapia génica en la prevención de neurodegeneración. Las enfermedades neurodegenerativas han sido de las más evaluadas en terapia génica, luego del cáncer y las enfermedades genéticas y metabólicas. Durante la última década, los científicos han avanzado mucho en la evaluación de terapias basadas en shRNA para las enfermedades que afectan el sistema nervioso central (SNC) (Boudreau, Davidson, 2010).

Para una serie de trastornos neurodegenerativos por ejemplo, la AD, la enfermedad de Parkinson (PD) y el deterioro post-infarto cerebral, la acumulación anómala de proteínas parece desempeñar un papel central en la aparición de la enfermedad o en la progresión (Aguzzi, O’Connor, 2010). Así, una modesta reducción en los niveles de proteínas neurotóxicas se espera que proporcione un significativo alivio terapéutico. Usando un enfoque basado en shRNA, los investigadores han inhibido con éxito la expresión de proteínas que causan enfermedades en modelos animales, donde, en la mayoría de los casos, ésta inhibición se correlaciona con la mejora de los fenotipos neuropatológicos y de comportamiento. Por ejemplo, la AD es la principal causa de demencia en todo el mundo y se caracteriza por la presencia de placas amiloideas y ovillos neurofibrilares (NFT) en el cerebro. En nuestra investigación (Piedrahita, et al., 2010) se bloqueó la producción de NFT en ratones triple-transgénicos para la $\mathrm{AD}$, silenciando la ciclina dependiente de quinasa 5 (CDK5), la cual es la encargada de hiperfosforilar la proteína tau y llevar a la formación de NFT. Por otro lado, la PD 
es la segunda enfermedad neurodegenerativa más común y ésta se caracteriza histopatológicamente por la formación de cuerpos de Lewy en el cerebro, los cuales son agregados compuestos principalmente de la proteína alfa-sinucleina ( $\alpha$-syn) (Halliday, GMcCann, 2010). Una sola mutación en $\alpha$-syn, así como la duplicación o triplicación genética del gen están vinculados a parkinsonismo hereditario, lo que llevó a los investigadores a utilizar el shRNA como un agente terapéutico verosímil en la PD (Sapru, et al., 2006).

Estudios preclínicos de terapia génica en infarto cerebral. La terapia génica utilizando shRNA tiene el potencial de ser aplicada para el tratamiento de lesiones cerebrales agudas en humanos debido a que su eficacia ha sido confirmada en modelos de infarto cerebral (Fukuda, Badaut, 2013). Varios estudios reportan resultados satisfactorios sobre la administración de shRNA en el modelo de la oclusión transitoria de la arteria cerebral media (t-MCAO) dirigidos a dianas terapéuticas que participan en la fisiopatología post-isquémica, desde la muerte celular apoptótica hasta la inflamación (Tabla 1).

Al principio, los investigadores se centraron en estrategias neuroprotectoras para limitar la propagación de las vías de muerte celular por apoptosis. El primer estudio utilizó un shRNA contra Beclin1, una proteína responsable de la autofagia celular y la apoptosis. Las ratas tratadas con shRNA para Beclina1 mostraron disminución de volumen del infarto y una mejora de los resultados neurológicos, así como disminución de la apoptosis (Zheng, et al., 2009). Del mismo modo, en un modelo de rata inducido con la inyección de la endotelina 1 y utilizando un shRNA contra la caspasa-3, se mostró una disminución de la apoptosis y una mejora en la recuperación funcional de la extremidad anterior (AlJamal, et al., 2011). Un estudio publicado en el mismo año, tuvo como diana terapéutica a otra proteína implicada en la cascada apoptótica, la quinasa reguladora de la señal apoptótica quinasa 1 (ASK1). Como el nombre lo indica, ASK1 juega un papel en la apoptosis y la diferenciación celular, así pues, los ratones tratados con el shRNA para ASK1 mostraron disminución del volumen del infarto y de la muerte celular (Kim, Cho, Lee, Kim, 2011). Sin embargo, es importante señalar que, en estos estudios, la administración del shRNA se produjo antes del evento isquémico, lo que limita los enfoques de la translación clínica.

Además, se ha intervenido compartimentos vasculares con un shRNA contra el receptor activado por la proteasa -1 (PAR-1) en un modelo de t-MCAO en ratón. PAR-1 está implicado en la coagulación sanguínea y sirve como otra opción viable para la estrategia trombolítica junto con el rtPA. El shRNA contra PAR-1 siete días antes de la lesión resultó en una disminución de volumen del infarto 24 y 72 $\mathrm{h}$ después de la lesión y un menor déficit neurológico en las mismas ventanas de tiempo evaluadas (Price, et al., 2010). Adicionalmente en la isquemia cerebral, la hipoxia que resulta de la reducción en la entrega de oxígeno al cerebro,

Tabla 1. Estudios in vivo usando shRNA en modelos de isquemia cerebral

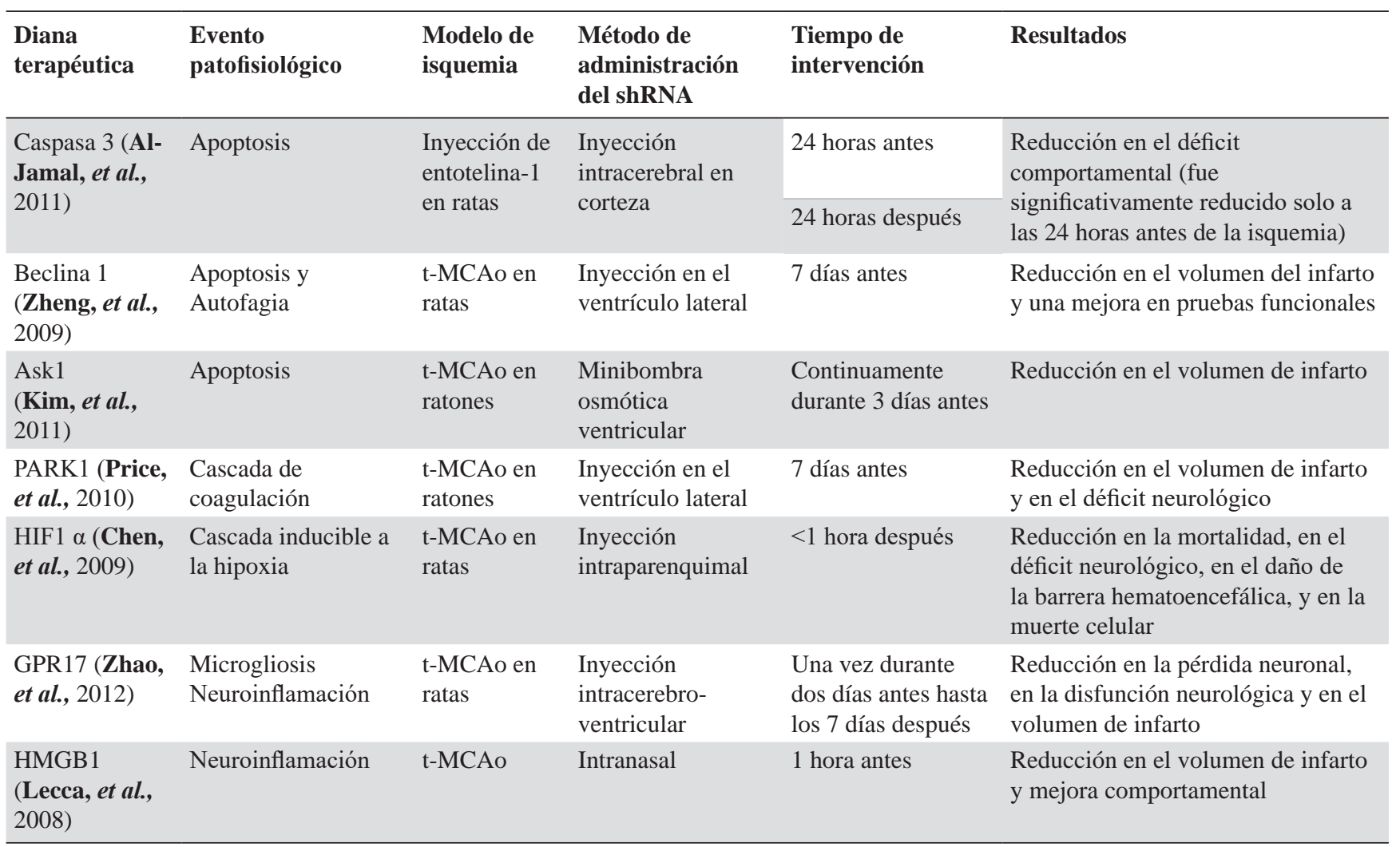


tiene enormes efectos sobre la muerte celular. Una proteína clave en este punto es el factor 1 inducible por hipoxia (HIF1 $\alpha$ ), que es inducido después del accidente cerebrovascular y está implicado en la disfunción de la unidad neurovascular. Al utilizarse un shRNA para HIF1 $\alpha$ una hora después de la t-MCAO en ratas, se disminuyó la disrupción de la barrera hematoencefálica, se produjo una disminución de la mortalidad y disminución del volumen del infarto, lo cual se asoció con mejoras en el comportamiento. Estos resultados fueron concomitantes con una menor expresión de la proteína p53 y menor actividad de la caspasa-3 (Chen, et al., 2009), generando grandes expectativas de traslación en situación post-infarto cerebral.

Otro mecanismo de lesión importante es la neuroinflamación. En un estudio reciente, la administración repetida de shRNA contra un blanco de la vía neuroinflamatoria brindó la oportunidad de estudiar los efectos agudos y crónicos de la administración de un shRNA (Zhao, et al., 2012). Los autores de dicho trabajo intervinieron la proteína G acoplada al receptor 17 (GPR17), una proteína con funciones propuestas en la neuroinflamación post-isquémica. Estudios previos en los que GPR17 se inhibió mediante un oligonucleótido antisentido, mostraron efectos benéficos después del accidente cerebrovascular isquémico (Lecca, $\boldsymbol{e t}$ al., 2008). Zhao, et al., 2012, examinaron específicamente el efecto de shRNA contra GPR17 en la activación microglial en las etapas aguda y crónica. En el estudio lograron reducir la microglía luego de 14 días, pero no a las 24 horas después de la lesión.

Otras proteínas importantes durante la fase neuroinflamatoria post-isquémica son las proteínas de alta movilidad del grupo de caja 1 (HMGB1), secretadas por las células necróticas para el reclutamiento de células pro-inflamatorias (Bianchi, Manfredi, 2007). Se encontró que una Inyección intracortical de shRNA contra HMGB1 tuvo efecto neuroprotector después del accidente cerebrovascular isquémico a través de la reducción de la activación microglial y la apoptosis neuronal (Kim, et al., 2006, 2010). En experimentos posteriores, la administración intranasal de este shRNA en un modelo de rata de t-MCAO, dio lugar a una reducción significativa de la HMGB1 en varias regiones del cerebro, pero no en hígado, pulmón, riñón, o corazón. Además, esta reducción efectiva se correlacionó con mejoras en las pruebas de comportamiento (Kim, et $\boldsymbol{a l .}$, 2012). Un punto importante a resaltar en este estudio en particular fue su método de administración. Aunque el shRNA fue administrado antes de la lesión, se utilizó una administración intranasal, por tanto, se evitó uno de los mayores obstáculos para la administración de fármacos al cerebro: la barrera hematoencefálica. Importante resaltar que la administración intranasal es una de las herramientas más prometedoras cuando se quiere proponer una terapia con una perspectiva de translación clínica, no sólo para la entrega de shRNA en el cerebro, sino también para la entrega de otro tipo de fármacos (Thorne, et al., 2004, 2008).
CDK5 como blanco terapéutico en el tratamiento del infarto cerebral. La quinasa-dependiente de ciclina 5 (CDK5) es una quinasa serina/ treonina, miembro de la familia de quinasas dependientes de ciclinas. De forma similar a otros miembros de este grupo de quinasas, CDK5 necesita unirse a una subunidad reguladora para ser activada. Sin embargo, esta quinasa no requiere la unión a ciclinas para su activación y, a cambio de ello, se asocia con activadores denominados p35 y p39, los cuales son estructuralmente similares a las ciclinas (Lopes, Agostinho, 2011).

En contraste con otros miembros de esta familia de quinasas, CDK5 no se encuentra directamente involucrada con el progreso del ciclo celular y su actividad predomina en neuronas post-mitóticas (Tsai, $\boldsymbol{e t}$ al., 1993) dado que sus activadores p35 y p39 son expresados principalmente en SNC (Zheng, Leung, Liem, 1998). Sin embargo, aunque la actividad de CDK5 es vital para el correcto desarrollo del SNC, su desregulación ha mostrado tener un papel crítico en el proceso neurodegenerativo crónico de varias enfermedades, incluidas la AD y la PD, la esclerosis lateral amiotrófica (ELA) y también después de una lesión aguda causada por una isquemia cerebral (Alvira, et al., 2008).

CDK5 en la sinapsis: funciones y disfunciones. CDK5 juega un papel importante en una variedad de procesos fisiológicos y patológicos. Esta multifuncionalidad incluye la participación en el desarrollo del sistema nervioso, la plasticidad sináptica y la neurodegeneración (Lopes, et al., 2011; Angelo, Plattner, Giese, 2006). El SNC requiere la migración programada, la diferenciación y la conexión de las neuronas para formar circuitos funcionales capaces de expresar la plasticidad sináptica (Angelo, et al., 2006). Estudios en varias líneas de ratones mutantes han demostrado que CDK5 es fundamental para todas estas etapas de desarrollo del SNC. Fenotípicamente ratones mutantes nulos para CDK5, así como doble mutantes para p35 / p39, exhiben una alteración de la arquitectura laminar cortical, así como trastornos en la citoarquitectura en el cerebelo, tronco cerebral y el hipocampo (Ko, et al., 2001).

En la pre y post sinápsis sw producen mecanismos moleculares de la plasticidad sináptica, los que implican la regulación de la liberación vesicular, cambios en la conductancia de los canales iónicos y modulación de actividades quinasa y fosfatasa (Vautrin, Barker, 2003). Diversas investigaciones han mostrado que CDK5 presenta una importante contribución en la plasticidad sináptica en cada uno de estos niveles y han implicado a CDK5 en la fosforilación directa de numerosos sustratos relevantes para la plasticidad sináptica, por ejemplo los receptores ionotrópicos de glutamato, proteínas de adhesión celular y proteínas del citoesqueleto (Lopes, et al., 2011; Angelo, et al., 2006). Dentro de las proteínas del citoesqueleto que son sustrato directo de CDK5 está la proteína Tau, la cual participa en el ensamble y desensamble de microtúbulos a través de la incorporación dinámica de monómeros de tubulina para formar los axones y dendritas neuronales; 
los cuales contribuyen al mantenimiento de la forma y del transporte celular. Tau también establece vínculos entre microtúbulos y otros elementos del citoesqueleto como los neurofilamentos $\mathrm{u}$ otras proteínas como son la espectrina y filamentos de actina. En el cerebro normal, el equilibrio entre fosforilación, así como la defosforilación de Tau por parte de CDK5, de otras quinasas y fosfatasas, origina cambios estructurales y conformacionales, lo que regula la estabilidad del citoesqueleto y, consecuentemente, la morfología axonal (Kimura, Ishiguro, Hisanaga, 2014).

Otra de las grandes funciones de CDK5 correlacionado a su papel en plasticidad sináptica, es en el aprendizaje y la memoria (Angelo, et al., 2006). En particular, los modelos transgénicos en animales han revelado papeles algo opuestos en cuanto al papel de CDK5 en el aprendizaje y la formación de la memoria. Un papel positivo de CDK5 se identificó en ratones $\mathrm{p}^{35^{-/}}$, los cuales muestran depotenciación, reducción de la LTP y la inducción defectuosa de la depresión a largo plazo (LTD), mecanismos que son electrofisiológicos relacionados con la formación de la memoria (Ohshima, et al., 2005). Del mismo modo, ratones Cdk5f/f /T29 en los que no hay expresión de CDK5 en las neuronas piramidales CA1 del hipocampo, revelaron un deterioro de la memoria y la plasticidad sináptica (Guan, et al., 2011) En contraste, Hawasli, et al., 2007, demostraron que la pérdida inicial de CDK5 en un modelo de ratón knockout condicional, genera una mayor LTP y mayor plasticidad mediada por los receptores NMDA y una mejora en el rendimiento de tareas como el aprendizaje.

Pese a las funciones que cumple CDK5 en plasticidad, desarrollo neuronal y memoria, su sobre-activación desencadena eventos neurodegenerativos que van desde muerte celular, desestabilización de los microtúbulos, alteración del citoesqueleto de actina, pérdida de la adhesión celular y alteraciones de memoria y aprendizaje. La desregulación de la actividad de CDK5 se inicia con el corte de sus activadores p35 y p39 a través de las calpaínas, las cuales son un grupo de proteasas citosólicas activadas por el calcio intracelular (Camins, et al., 2006).

Después de un evento isquémico la sobre-activación de receptores de glutamato de tipo NMDA y AMPA conlleva a un incremento de calcio intracelular con activación las calpaínas, las cuales cortan a los activadores p35 y p39 para generar a p25 y p29, respectivamente (Figura 2). La vida media de p25 y p29 es significativamente más larga (alrededor de tres veces mayor a la de p35 y p39), así como la unión a la quinasa de estos activadores, lo que es mucho más fuerte que la unión de p35 y p39 (Patrick, et al., 1998; Amin, Albers, Pant, 2002); ello resulta en un aumento de la actividad de p25/CDK5 (o p29), en comparación con p35/CDK5 (o p39). Por otro lado, p25 y p29 carecen de un sitio de miristoilización amino-terminal, modificación necesaria para mantener la proteína en la periferia de la célula, en la membrana celular (Asada, et al., 2008). De esta manera, la interacción de p25 con CDK5 no solo conlleva una activación de la quinasa de una manera sostenida en el tiempo, sino que modifica su distribución celular, concentrándose en el citoplasma y en el núcleo, alterando su especificidad de sustratos y desencadenando la muerte celular (Asada, et al., 2008; Patrick, et al., 1999).

Se ha encontrado que en ratas la expresión CDK5, así como el clivaje de p35, aumenta en las neuronas de la región de penumbra después de la oclusión de arteria cerebral media (MCAO) (Wen, et al., 2007) y, más recientemente, se anotó también una asociación entre el incremento en la expresión de CDK5 y del fragmento clivado p25 con daño neuronal en cerebros de pacientes afectados por una isquemia cerebral (Mitsios, et al., 2007).

Adicionalmente, modelos in vivo indican que, el aumento sostenido de la actividad de CDK5 en la AD se correlaciona con la hiperfosforilación aberrante de la proteína Tau, formando agregados de esta proteína en el soma (Piedrahita, et al., 2010) y, por consiguiente, la inducción de muerte celular, pérdida de habilidades de aprendizaje y memoria (Posada-Duque, et al., 2015). Se ha demostrado que ratones que sobre-expresan p25 durante largos períodos de tiempo, sufren deterioro de la LTP en el hipocampo y déficits de memoria, junto con una significativa pérdida neuronal. Sin embargo, cuando p25 se expresa de forma transitoria, se mejora la LTP, aumenta el número de espinas dendríticas y de sinapsis, sin observar neurodegeneración (Fischer, et al., 2005).

\section{Excitotoxicidad por glutamato}

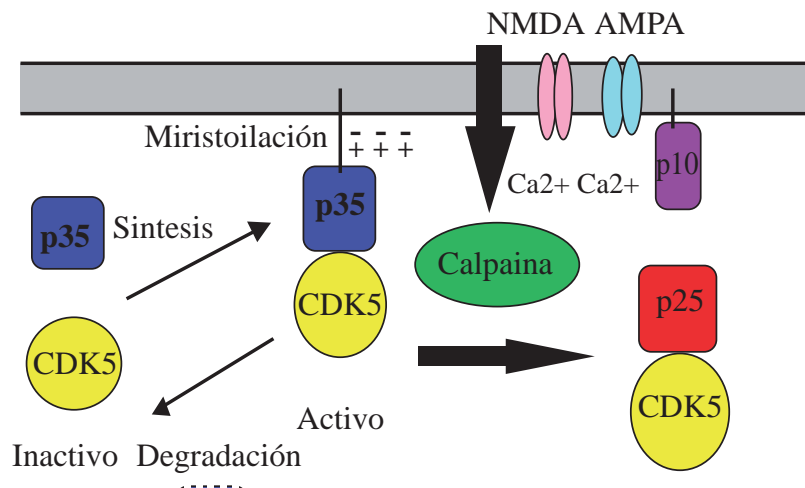

$$
\text { sp35 }
$$

Hiperactivo

\section{Condición fisiológica}

Isquemia cerebral

Figura 2. Mecanismo de activación de CDK5. CDK5 por sí sola es una subunidad catalítica inactiva. Esta quinasa es activada por p35 y luego reclutada a la membrana a través de la miristoilación de su región $\mathrm{N}$-terminal. p35 es una proteína con un lapso de vida corta y es degradada por el proteosoma. Cuando se presenta una condición de excitotoxicidad por glutamato como en el caso de la isquemia cerebral, la calpaína se activa por el incremento de las concentraciones de calcio intracelular y corta a p35 en un fragmento C-terminal generando a p10 y a p25. p25 tiene una vida media más larga y se disocia de las membranas, donde es capaz de mantener de forma sostenida la fosforilación de CDK5. 
Estrategias para controlar la sobre-activación de CDK5. Debido a la importancia que tiene CDK5 en neurodegeneración, es de suponer que esta quinasa es una buena diana terapéutica para prevenir o, incluso, detener patologías asociadas a la hiperfosforilacion de Tau, como ya ha sido demostrado en la AD (Piedrahita, et al., 2010). De hecho, diversos estudios in vitro e in vivo han demostrado que el bloqueo de la sobre-actividad de CDK5 puede tener un efecto benéfico y que genera neuroprotección. Se han utilizado dos estrategias principales para estos fines: la inhibición directa, con el uso de inhibidores de CDK5, y la acción indirecta mediante la prevención de la excesiva generación del activador p25 asociada, a través del uso de inhibidores de calpaína (Lopes, et al., 2011).

Algunos estudios muestran que la roscovitina, un inhibidor farmacológico de CDK5, ejerce un efecto neuroprotector in vivo, después de su administración sistémica pre y postisquemia en modelos experimentales del accidente cerebrovascular (Menn, et al., 2010) La roscovitina actúa en diferentes tipos de células (neuronas y células gliales) y a través de diversos mecanismos tales como anti-apoptóticos, anti-excitotoxicidad y, posiblemente, mediante las vías antiinflamatorias. De esta manera, incluso cuando la roscovitina es administrada dos horas post-isquemia, se reduce el volumen de infarto en ratas sometidas a una isquemia focal transitoria (Lopes, et al., 2011). Por otro lado, un inhibidor de calpaína (MDL 28.170), reduce el volumen de infarto cuando se administra 30 minutos después de la oclusión de la arteria cerebral media. Adicionalmente, en este mismo estudio se evaluaron diversas ventanas terapéuticas para determinar el retardo máximo entre el inicio de la isquemia y la eficacia de la terapia, encontrando que el MDL 28.170 reduce el volumen del infarto cuando la terapia se retrasa durante $0,5,3$, 4, y 6 horas después del inicio de la isquemia. El efecto protector de MDL 28.170 se pierde después de un retraso de 8 horas (Markgraf, et al., 1998).

A pesar de que ambos abordajes mediante el uso común de inhibidores farmacológicos de CDK5 y los inhibidores de calpaína tienen la capacidad de cruzar la barrera hematoencefálica, además de mostrar reducción en el volumen de infarto, la muerte celular y la respuesta inflamatoria en una amplia ventana terapéutica de intervención, éstos no son completamente específicos (Fischer, et al., 2001; Glicksman, et al., 2007), lo que implica que su administración puede afectar también otro tipo de proteínas involucradas en otras vías de señalización celular.

Es así como estudios realizados en los últimos años, han mostrado otras perspectivas para controlar la sobreactivación de CDK5. Por ejemplo, un péptido diseñado para inhibir CDK5 protege en varios modelos in vivo de enfermedades neurodegenerativas como AD (Binukumar, et al., 2015, 2015a), PD (Binukumar, et al., 2015) e infarto cerebral (Tan, et al., 2015). Este péptido de 24 aminoácidos es capaz de atravesar la barrera hematoencefálica. In vitro, estos péptidos inhiben la actividad de p35/CDK5 y p25/
CDK5, mientras que, en las neuronas corticales de roedores, sólo inhiben a p25/CDK5 sin afectar la actividad endógena de p35/CDK5. En un modelo de isquemia cerebral, el tratamiento con el péptido p5-TAT no altera los niveles de p35, p39, aunque reduce la fosforilación de Tau a través de la inhibición de la actividad p25/CDK5. Además, p5-TAT reduce los niveles de la caspasa-3 y el volumen del infarto cerebral; incluso cuando p5-TAT es administrado hasta 24 horas después de la lesión isquémica, lo que promueve la recuperación funcional a largo plazo (Tan, et al., 2015).

En nuestro grupo de investigación se ha evaluado el efecto del silenciamiento de CDK5 en AD (Piedrahita, et al., 2010, Castro-Alvarez, et al., 2014a; Castro-Alvarez, Uribe-Arias, Cardona-Gómez, 2014b; Castro-Alvarez, Uribe-Arias, Cardona-Gomez, 2015). AD es una enfermedad neurodegenerativa en donde la sobre-activación de CDK5 y la consiguiente taupatía y alteración cognitiva, son el común denominador con la isquemia cerebral. Utilizando un iRNA para CDK5 inyectado en ratones triple transgénicos para $\mathrm{AD}$, se encontró una reducción de la hiperfosforilación de Tau y de placas beta amiloide, así como una mejora en el aprendizaje y la memoria espacial en estos ratones, tanto a corto como a largo plazo del tratamiento.

Silenciamiento de CDK5 a través de RNA de interferencia en isquemia cerebral. Los anteriores antecedentes ponen de manifiesto que el silenciamiento de CDK5 puede ser una herramienta clave en la reversión del daño tras una isquemia cerebral. Lo anterior parte del hecho de que el bloqueo de CDK5 puede prevenir varios eventos patológicos que se dan en el lapso de tiempo desde las primeras horas hasta, incluso, meses post-lesión. Por ejemplo, después de la isquemia cerebral, la muerte neuronal que se presenta como un evento temprano de la cascada fisiopatológica, se asocia fundamentalmente por la hiper-activación de CDK5 mediada por p25. El silenciamiento de CDK5 puede estar jugando un papel crítico a tiempos tempranos en la regulación de la tasa de degradación y en la internalización de los receptores NMDA, los cuales son elementos esenciales en toda la cascada excitotóxica que se presente luego de un daño isquémico y, por ende, evitando el consecuente incremento en la entrada de calcio intracelular, la activación de calpaínas y la activación de vías de muerte celular. Lo anterior se basa en que la subunidad GluN2B del receptor NMDA es sustrato directo de CDK5, fosforilación que determina la dinámica de internalización del receptor (Zhang, et al., 2008).

Una ventaja del control de la sobre-activación de CDK5 a través de un iRNA además de su alta especificidad, es su permanencia a largo término, ya que ello permite la prevención de los eventos fisiopatológicos que pueden aparecer luego de varios meses post-isquemia. Nuestras investigaciones muestran que la terapia génica dirigida a silenciar CDK5 en el hipocampo derecho de ratas isquémicas durante la oclusión de la arteria cerebral media (tMCAO), no genera cambios en los parámetros fisiológicos (presión arterial, $\mathrm{pH}, \mathrm{pO} 2, \mathrm{pCO} 2$ ) ni en la reducción de CDK5, lo 
que resultó en una mejoría neurológica y motora durante la primera semana después de la isquemia. Así mismo, impidió disfunciones en el aprendizaje, la memoria y la reversión de aprendizaje a un mes, y se mantuvo la protección a los cuatro meses post-isquemia, además previno pérdida neuronal, taupatía e hiperreactividad microglial (GutierrezVargas, et al., 2015), dicho efecto se mantuvo por cuatro meses (Gutiérrez-Vargas, Moreno, Cardona-Gómez, 2016). El silenciamiento de CDK5 aumentó la expresión del factor neurotrófico derivado del cerebro (BDNF) y activó la ruta de TRKB/ CREB / CaMKII en el hipocampo, implicando la modulación de calcio en las espinas y la inducción de LTP, en un modo dependiente de receptor TRKB en las neuronas (Gutierrez-Vargas, et al., 2016; Posada-Duque, et al., 2017). También, CDK5 iRNA protegió contra la excitotoxicidad mediada por glutamato (principal neurotransmisor excitatorio que aumenta de manera descontrolada en un infarto cerebral) en cultivos primarios de neuronas. La protección fue dependiente de un aumento concomitante de p35, ya que se bloqueó al utilizar un iRNA contra p35, lo que afectó corriente abajo la actividad de las RhoGTPasas (proteínas encargadas del remodelamiento del citoesqueleto y formación de espinas dendríticas). Además, la sobreexpresión de la proteína p35, así como la versión de la constitutivamente activa de Rac1, imitaron la neuroprotección ejercida por el silenciamiento de CDK5 (Posada-Duque, et al., 2015). Otras proteínas sinápticas, también participaron en la neuroprotección y plasticidad inducida por el iRNA de CDK5, como fueron: PSD95, NR2B, p120ctn, Ncadherin y $\beta$-catenina. La inhibición o "knock-out" de CDK5 dieron como resultado el aumento de p120ctn y la neuroprotección inducida por CDK5 iRNA dependió de la expresión de p120ctn en un modelo de excitotoxicidad inducida por glutamato (UribeArias, et al., 2016). Así el complejo p35/p120ctn/PSD95/ NR2B está implicado en la recuperación sináptica inducida por el silenciamiento de CDK5.

Por otro lado, los astrocitos realizan funciones metabólicas y de soporte estructural en el cerebro y contribuyen a la integridad de la barrera hematoencefálica. Los astrocitos influyen en la supervivencia neuronal y previenen la gliotoxicidad mediante la captura de glutamato (Glu), especies reactivas de oxígeno y nutrientes. CDK5 podría tener un doble efecto sobre el endotelio y los astrocitos, ya que está involucrada en migración, senescencia y angiogénesis, y su hiperactividad está asociada con la disfunción de la recaptura de glutamato e hipoxia. Por lo tanto, la terapia génica basada en el silenciamiento de CDK5, es una estrategia muy promisoria en la prevención del deterioro cerebral progresivo. En la línea celular C6 astroglioma y astrocitos primarios, CDK5 RNAi evitó la gliotoxicidad inducida por el glutamato, efecto que fue confirmado por la inhibición farmacológica de CDK5 con roscovitina (Rosc). El fenotipo del astrocito silenciado, presentó la formación de lamellipodia, tras la activación de Rac1 y la liberación de BDNF. Eventos que fueron responsables de la protección de neuronas expuestas a la excitotoxicidad por glutamato y en co-cultivo con los astrocitos- CDK5 "knock-down" (KD). De interés, la inhibición de Rac1 en astrocitos bloqueó el aumento del BDNF y la neuroprotección (Posada-Duque, $\boldsymbol{e t}$ al., 2015). Así el remodelamiento del citoesqueleto de actina en el estrellamiento de los astrocitos, sugiere un fenotipo funcional para la liberación de BDNF, el cual promueve la neuroprotección.

En forma complementaria, en la línea celular de bEnd.3 proveniente de microvasculatura cerebral de ratón, se encontró que Rosc recuperaba la adhesión endotelial alterada por la toxicidad del glutamato; este efecto fue corroborado por el aumento de la TEER, p120ctn, y la reducción de las hendiduras intercelulares. Además, CDK5 iRNA incrementó los procesos primarios en células bEnd.3, que se relacionan con la formación similar a lamelipodios. Por otro lado, las células endoteliales que se co-cultivaron con astrocitos CDK5 iRNA mostraron una recuperación de la viabilidad celular, un aumento de las proteínas de adhesión (p120ctn y PECAM-1), y un aumento en la liberación de BDNF. Estos hallazgos sugieren que la inhibición de CDK5, o su silenciamiento en astrocitos, protege el endotelio, lo que promueve la liberación de BDNF y la adhesión endotelial (Posada-Duque, Vargas-Restrepo, Cardona-Gómez, datos no publicados). Estos hallazgos validan preclínicamente el uso de los astrocitos CDK5 - KD, como una alternativa de terapia celular, que recupera la integridad de la unidad neurovascular en infarto cerebral. Por lo tanto, se evaluó en ratas la respuesta del parénquima cerebral al trasplante de astrocitos-CDK5 KD en la corteza somatosensorial después de una isquemia cerebral. En estos experimentos se logró una prevención general de la pérdida neuronal por el trasplante de astrocitos CDK5-KD, los cuales indujeron una estimulación significativa en la arborización de astrocitos endógenos, envolviendo vasos sanguíneos, acompañado por el aumento de la inmunoreactividad de PECAM-1 en las áreas motora y somatosensorial, así como un aumento de Ki67 (marcador de proliferación) en los ventrículos laterales, parcialmente asociados a la producción BDNF, lo que sugiere que el trasplante de astrocitos CDK5-KD protege la unidad neurovascular, recupera la función motora y neurológica en las ratas isquémicas (Becerra-Calixto, Cardona-Gómez, 2016).

En conjunto, los resultados obtenidos en esta investigación sugieren que la unidad neurovascular tiene un papel crítico en la recuperación funcional y morfológica después de un infarto cerebral y que el silenciamiento de CDK5 en neuronas, astrocitos y endotelio genera protección. No obstante, nuestros resultados sugieren que los astrocitos CDK5-KD son una fuente paracrina de la producción de BDNF, el que genera protección neuronal y endovascular, lo cual se convierte en una estrategia novedosa en la protección de la integridad BBB después de un accidente cerebrovascular. 
Lo anterior, apoyado por otras investigaciones que se han centrado en nuevas terapias dirigidas a mejorar la angiogénesis, eventos que son críticos en la recuperación a mediano y largo termino post-daño cerebral, han puesto de manifiesto a la inhibición de la señalización p25/ CDK5 como un nuevo blanco de intervención para la protección celular y recuperación de la remodelación tisular después del accidente cerebrovascular (Slevin, Krupinski, 2009).

Como vemos, el silenciamiento de CDK5 en el contexto de acción terapéutica, es una estrategia ideal porque no solo contempla eventos troncales en el fenómeno de isquemia/reperfusión como posiblemente la excitoxicidad por glutamato, al bloquear consecutivamente fenómenos fisiopatológicos asociados como activación de calpaínas, activación de rutas de muerte, e hiperfosforilación de Tau (Figura 3), sino que - de igual manera - es posible llegar a abordar otros eventos que son críticos en la recuperación a largo término como lo son la plasticidad sináptica, la angiogénesis y la neurogénesis. Ello, en conjunto, podría desencadenar una mejoría en funciones alteradas, motora, cognitiva y emocional, luego de una isquemia cerebral.

Actuales y futuros desafíos de la terapia génica en infarto cerebral desde el punto de vista de la medicina translacional. De acuerdo con todo lo abordado anteriormente entre ellos nuestros propios estudios y a pesar de haber identificado blancos moleculares potenciales, hay limitaciones considerables inherentes al sistema nervioso, tales como el cruce de la barrera hematoencefálica y la dificultad para dirigirse a poblaciones neuronales de regiones específicas (hipocampo, corteza, tálamo). La existencia de estos obstáculos, ha impulsado hacia la búsqueda de nuevas estrategias para el tratamiento de enfermedades neurodegenerativas, tales como el uso de vectores virales, el diseño de nanopartículas y la terapia celular con el fin de

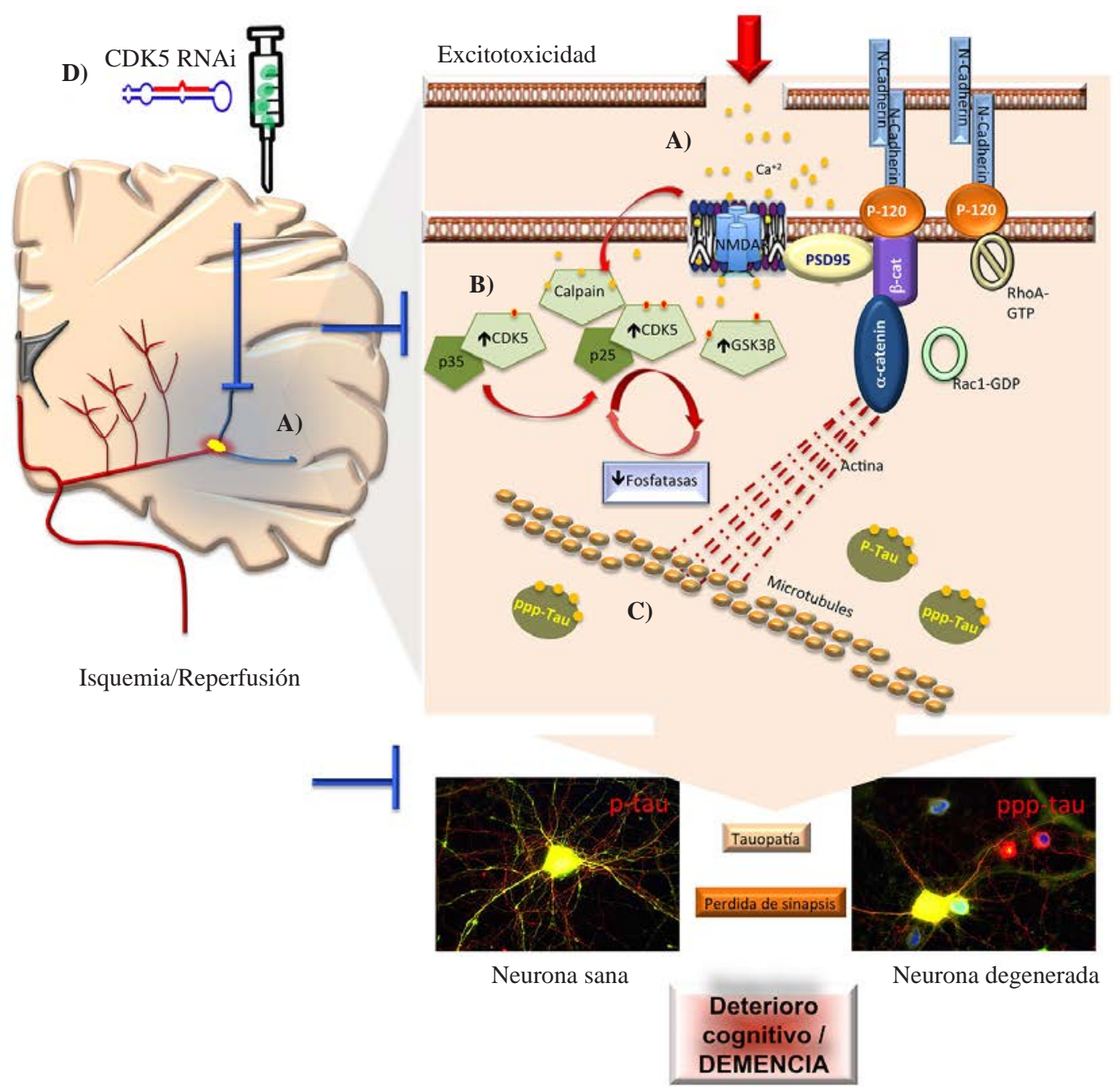

Figura 3. Modelo hipotético de la acción de la terapia génica basada en la interferencia del CDK5 ante un evento de excitotoxicidad por infarto cerebral isquémico y prevención del deterioro cognitivo. A) Anoxia/reperfusión, y propagación de la excitoxicidad, B) Activación de CDK5, disbalance quinasas/fosfatasas, hiperfosforilación de Tau, C) Desensamblaje del citoesqueleto de actina y microtúbulos, pérdida de sinapsis, deterioro cognitivo y demencia. D) La terapia génica con CDK5 iRNA bloquea los eventos anteriores (A-C). pTau: Fosforilación de tau, pppTau: hiperfosforilación de tau 
mejorar la liberación del transgene y subsanar las limitaciones en cuanto a las vías de administración, incluyendo estudios de seguridad y eficacia, que aún representan un desafío.

Una limitación importante de la mayoría de estudios realizados en terapia génica en infarto cerebral es la aplicabilidad al paciente. Hay dos aspectos que son cruciales a la hora de llevar los resultados de los estudios preclínicos al paciente: el tiempo de intervención terapéutica y la vía administración para que el shRNA llegue directamente a la zona infartada (Fukuda, et al., 2013).

La mayoría de estudios donde se han encontraron los mejores resultados terapéuticos son aquellos donde la administración del shRNA se hace antes de la lesión. Desafortunadamente, un pre-tratamiento con shRNA representa un problema porque no imita la demanda clínica de intervención. Como se ha sido demostrado por Al-Jamal, et al., 2011, un tratamiento administrado en diferentes momentos, ya sea antes o luego de la lesión, podría producir diferentes efectos, lo cual incluye que el shRNA administrado antes de la lesión o luego de horas o de días después de la lesión, pudiera tener un efecto diferencial en la recuperación isquémica (Al-Jamal, et al., 2011). El siguiente paso, entonces, es poner a prueba la eficacia de la terapia cuando el shRNA es administrado por lo menos poco tiempo después de la lesión, imitando así los plazos previstos en la práctica clínica. En esto punto ya se han venido realizando estudios con resultados satisfactorios (Tabla 1).

La vía de administración intracerebral del shRNA presenta la mayor dificultad en el uso clínico de la terapia génica por el riesgo en la intervención quirúrgica, y la aplicación por vía intravenosa, que ¿ ? no atraviesa la barrera hematoencefálica. Los métodos que, hasta el momento, han sido empleados en modelos in vivo de isquemia cerebral en roedores, han sido la inyección intracerebroventricular, inyección intra-parenquimatosa y en la arteria carótida interna (Kim, et al., 2011). Otro estudio analiza como la disminución de la expresión de claudina 5 con una inyección en la cola del ratón, y su localización, se facilita debido a que dicha proteína hace parte de la barrera hematoencefálica y, por lo tanto, no hay necesidad de que el shRNA la cruce. Sin embargo, debido a que la claudina-5 está presente en otros órganos, vale la pena señalar que la expresión del shRNA fue eficaz también en las células hepáticas y endoteliales (Campbell, et $\boldsymbol{a l}$. , 2012). Otro estudio empleo el método de la administración intranasal con éxito, ya que permitió acceder directamente al cerebro (Kim, et $\boldsymbol{a l}$. , 2012).

Esta administración intranasal es un método no invasivo, de sencilla elección, eficiente en tiempo, rentable y que proporciona facilidad del procedimiento. Frey y sus colaboradores, pioneros en el campo de la administración de fármacos por vía intranasal en enfermedades cerebrales como el ictus y la $\mathrm{AD}$, han mostrado resultados prometedores con una amplia variedad de compuestos, entre los cuales la insulina y el factor de crecimiento nervioso, proporcionan mejoras eficientes en la recuperación, sin efectos secundarios significativos (Danielyan, et al., 2010; Gomez, et al., 2012). En el caso de la terapia génica, el shRNA puede llegar directamente a las células del cerebro a través de la ruta intranasal, debido a que no se presentan impedimentos por la barrera hematoencefálica. Ya existe al menos un estudio en el que se administró por vía intranasal un shRNA en un modelo de accidente cerebrovascular rata y se obtuvieron resultados prometedores (Kim, et al., 2012). Otros estudios han observado que el shRNA administrado a través de la vía intranasal viaja eficazmente a los nervios olfatorios y bulbo olfatorio (Renner, Frey, Hanson, 2012), y a los núcleos del rafe dirigidos a las neuronas serotoninérgicas (Bortolozzi, et al., 2012). El trabajo realizado por Kim, et al., 2012, es muy promisorio porque el shRNA administrado por vía intranasal en un modelo de ratas t-MCAO, mostró una reducción significativa de la proteína diana en el cerebro. Dentro de la primera hora después de la administración intranasal, el shRNA se observó en el citoplasma de las neuronas, astrocitos y células de la microglía en la corteza frontal, el cuerpo estriado, la amígdala y el hipotálamo y se mantuvo durante al menos 12 horas después de la inyección. Sin embargo, los estudios farmacocinéticos son necesarios y pueden ofrecer garantías de la entrega efectiva del shRNA en el cerebro (Thorne, Frey, 2001).

Por otro lado, además de las dificultades inherentes del sistema nervioso central, la medicina de traslación a partir del descubrimiento de fármacos útiles para la clínica, necesita superar varias limitaciones, las que además de la sensibilidad y la especificidad de los fármacos, requiere que los pacientes deban estar clasificados con claros criterios de inclusión (Drucker, Krapfenbauer, 2013). Promover la traslación de alternativas terapéuticas que impacten la morbilidad y la mortalidad, es una necesidad urgente en todo el mundo y en Latino América. Específicamente en Colombia, necesitamos dar un paso adelante en las políticas de medicina de traslación, aunque nuestros países en desarrollo necesitan primero mejorar la atención médica de urgencias para lesiones agudas (Razzak, Kellermann, 2002). También necesitamos ponernos al día en normativas y protocolos para desarrollar ensayos clínicos con candidatos originales o estrategias propuestas por países de América Latina, y reunir esfuerzos de científicos, especialistas médicos, industria farmacéutica y gobierno, acompañados de apoyo económico y social. Debemos ofrecer tratamientos experimentales, sin falsas expectativas al paciente y a la familia, basados en el rigor de las evidencias científicas preclínicas, en diálogo directo con el equipo médico, la vigilancia por parte de los pares de las fases I, II y III, y la estricta monitorización a largo plazo de los efectos secundarios potenciales no deseados (Main, et al., 2014), podrían ir fortaleciendo progresivamente la contribución que permita resolver los problemas de salud mental (Cardona-Gómez, Lopera, 2016).

\section{Conclusiones}

La isquemia cerebral se ha convertido en una problemática de salud mundial, debido a su alta tasa de mortalidad y a 
la discapacidad que genera en los pacientes que la padecen. Se han evaluado muchas estrategias terapéuticas tanto en modelos experimentales como en ensayos clínicos sin obtener los resultados esperados. Dos de las grandes falencias de esta investigación terapéutica son la limitación en el tiempo de intervención (menos de cuatro horas y media) y el corto tiempo de protección (o seguimiento) de la terapia, lo cual genera en los pacientes secuelas a largo término.

La terapia génica ha mostrado ser una herramienta de gran utilidad para el tratamiento de enfermedades neurodegenerativas; sin embargo específicamente en isquemia cerebral hay pocos estudios preclínicos, los cuales muestran efecto neuroprotector a través de la reducción en el volumen de infarto y una mejoría funcional, pero no logran un acercamiento a la solución clínica porque la intervención terapéutica se realiza antes de inducir el infarto cerebral. Por lo tanto, un gran reto de la terapia génica es que sea implementada como terapia post-lesión, lo cual es apoyado por nuestros resultados, ya que esta situación recrea la necesidad del paciente una vez llega al hospital y los resultados experimentales toman mayor relevancia en el campo de la medicina de traslación.

El bloqueo de CDK5 se ha convertido en una estrategia terapéutica de alta importancia para reducir la muerte celular en varias enfermedades neurodegenerativas, principalmente en aquellas donde la taupatía es la causante del deterioro cognitivo y demencia, como es el caso de la isquemia cerebral (Figura 3). Sin embargo, pese a que se han probado inhibidores farmacológicos para dicha quinasa es necesario el uso de metodologías que permitan el bloqueo dirigido y eficaz de CDK5, evitando así efectos secundarios de la terapia generados por bloqueos farmacológicos inespecíficos hacia otras proteínas y vías de señalización. Es aquí donde la terapia génica, cobra gran importancia siendo esta una herramienta dirigida para controlar la sobre-activación de dicha quinasa, no solo en un tiempo inmediato a la lesión isquémica en el cual hay mayor tasa de muerte celular, sino que también su efecto permanece a largo término, donde se puede prevenir la disfunción emocional y cognitiva, se evita la pérdida de espinas y dendritas, que son eventos fundamentales en las secuelas a largo plazo post-isquemia. Por lo tanto, los primeros pasos deberán ser la solicitud y aprobación de protocolos de ensayos clínicos por el INVIMA (ente regulatorio de seguridad y eficacia de medicamentos y alimentos en Colombia), la oferta de fuentes de financiación provenientes del gobierno y la empresa que incentiven el desarrollo de terapias propuestas desde nuestro propio país. Lo anterior significaría un alineamiento entre los intereses científicos, del gobierno y del sector productivo, que ayudarían a evitar o a mejorar la calidad de vida de los pacientes con incapacidad física y mental post-infarto cerebral.

\section{Agradecimientos}

Agradecemos al Área de Neurobiología Celular y Molecular, Grupo de Neurociencias de Antioquia (GNA), de la Universidad de Antioquia por la discusión académica constructiva.
Esta investigación fue apoyada por proyectos de Colciencias (código \# 111551928905, \# 111554531400) (GPC-G) y el CODI de la Universidad de Antioquia.

\section{Conflicto de intereses}

Los autores declaran no tener ningún conflicto de interés.

\section{Referencias}

ADI/BUPA Inform. 2013. La demencia en América: EL costo y la prevalencia del Alzheimer y otros tipos de demencia.

Aguzzi, A., O’Connor, T. 2010. Protein aggregation diseases: pathogenicity and therapeutic perspectives. Nat Rev Drug Discov. 9: 237-48.

Al-Jamal, K.T., Gherardini, L., Bardi, G., Nunes, A., Guo, C., Bussy, C., Herrero, M.A., Bianco, A., Prato, M., Kostarelos, K., Pizzorusso, T. 2011. Functional motor recovery from brain ischemic insult by carbon nanotubemediated siRNA silencing. Proc Natl Acad Sci U S A. 108: 10952-7.

Alvira, D., Ferrer, I., Gutierrez-Cuesta, J., Garcia-Castro, B., Pallàs, M., Camins, A. 2008. Activation of the calpain/ cdk5/p25 pathway in the girus cinguli in Parkinson's disease. Parkinsonism \& related disorders. 14: 309-13.

Amlie-Lefond, C., Chan, A.K., Kirton, A., DeVeber, G., Hovinga, C.A., Ichord, R., Stephens, D., Zaidat, O.O. 2009. Thrombolysis in acute childhood stroke: design and challenges of the thrombolysis in pediatric stroke clinical trial. Neuroepidemiology. 32: 279-86.

Amin, N.D., Albers, W., Pant, H.C. 2002. Cyclin-dependent kinase 5 (cdk5) activation requires interaction with three domains of p35. J Neuros Res. 67: 354-62.

Angelo, M., F. Plattner, Giese, K.P. 2006. Cyclin-dependent kinase 5 in synaptic plasticity, learning and memory. $J$ Neurochem. 99: 353-70.

Asada, A., Yamamoto, N., Gohda, M., Saito, T., Hayashi, N., Hisanaga, S. 2008. Myristoylation of p39 and p35 is a determinant of cytoplasmic or nuclear localization of active cyclin-dependent kinase 5 complexes. $J$ Neurochem. 106: 1325-36.

Assarzadegan, F., Tabesh, H., Shoghli,. A, Ghafoori Yazdi M., Tabesh, H., Daneshpajooh, P., Yaseri, M. 2015. Relation of Stroke Risk Factors with Specific Stroke Subtypes and Territories. Iran J Public Health. 44:1387-1394.

Brainin, M., Tuomilehto, J., Heiss, W.D., Bornstein, N.M., Bath, P.M., Teuschl, Y., Richard, E., Guekht, A., Quinn, T. 2015. Post-stroke cognitive decline: an update and perspectives for clinical research. Eur J Neurol. 22: 229-38.

Becerra-Calixto,A., Cardona-Gómez, G.P.2016. Neuroprotection Induced by Transplanted CDK5 Knockdown Astrocytes in Global Cerebral Ischemic Rats. Mol Neurobiol.

Bejot, Y., Benatru, I., Rouaud, O., Fromont, A., Besancenot, J.P., Moreau, T., Giroud, M. 2007. Epidemiology of stroke in Europe: geographic and environmental differences. $J$ Neurol Sci. 262: 85-88.

Bianchi, M.E., Manfredi, A.A. 2007. High-mobility group box 1 (HMGB1) protein at the crossroads between innate and adaptive immunity. Immunol Rev. 220: 35-46.

Binukumar, B.K., Shukla, V., Amin, N.D., Bhaskar, M., Skuntz, S., Steiner, J., Winkler, D., Pelech, S.L., Pant, H.C. 2015. Analysis of the Inhibitory Elements in the p5 Peptide Fragment of the CDK5 Activator, p35, CDKR1 Protein. $J$ Alzheimers Dis. 48: 1009-17. 
Binukumar, B.K., Shukla V, Amin ND, Grant P, Bhaskar M, Skuntz S, Steiner J, Pant HC. 2015. Peptide (TFP5/TP5), derived from Cdk5 activator P35, provides neuroprotection in the MPTP model of Parkinson's disease. Mol Biol Cell. 26: 4478-4491.

Bortolozzi, A., Castañé, A., Semakova, J., Santana, N., Alvarado, G., Cortés, R., Ferrés-Coy, A., Fernández, G., Carmona, M.C., Toth, M., Perales, J.C., Montefeltro, A., Artigas, F. 2012. Selective siRNA-mediated suppression of 5-HT1A autoreceptors evokes strong anti-depressantlike effects. Mol Psychiatry. 17: 612-23.

Boudreau, R.L., Davidson, B.L. 2010. RNAi therapeutics for CNS disorders. Brain Res. 1338: 112-21.

Boudreau, R.L., Rodriguez-Lebron, E., Davidson, B.L. 2011. RNAi medicine for the brain: progresses and challenges. Hum Mol Genet. 20: R21-7.

Camins, A., Verdaguer, E., Folch, J., Pallàs, M. 2006. Involvement of calpain activation in neurodegenerative processes. CNS drug reviews. 2006. 12: 135-148.

Campbell, M., Hanrahan, F., Gobbo, O.L., Kelly, M.E., Kiang, A.S., Humphries, M.M., Nguyen, A.T., Ozaki, E., Keaney, J., Blau, C.W., Kerskens, C.M., Cahalan, S.D., Callanan, J.J., Wallace, E., Grant, G.. A, Doherty, C.P., Humphries, P. 2012. Targeted suppression of claudin-5 decreases cerebral oedema and improves cognitive outcome following traumatic brain injury. Nat Commun. 3: 849.

Cardona-Gómez, G.P. \& Lopera, F. 2016. Dementia, preclinical studies and its potential for translational medicine in South America. Frontiers in Aging Neurosci. 8: 304.

Castillo J, Alvarez-Sabin J, Dávalos A, Diez-Tejedor E, Lizasoain I, Martínez-Vila E, Vivancos J, Zarranz JJ. 2003 [Consensus review. Pharmacological neuroprotection in cerebral ischemia: is it still a therapeutic option?]. Neurologia. 18: 368-84.

Castro-Alvarez, J.F., Gutierrez-Vargas, J., Darnaudéry, M., Cardona-Gómez, G.P. 2011. ROCK inhibition prevents tau hyperphosphorylation and p25/CDK5 increase after global cerebral ischemia. Behav Neurosci. 125: 465-72.

Castro-Alvarez, J.F., Uribe-Arias, S.A., Kosik, K.S., CardonaGómez, G.P. 2014a. Long- and short-term CDK5 knockdown prevents spatial memory dysfunction and tau pathology of triple transgenic Alzheimer's mice. Front Aging Neurosci. 6: 243.

Castro-Alvarez, J.F., Uribe-Arias, S.A., Cardona-Gómez, G.P. 2014b. Cyclin-dependent kinase 5, a node protein in diminished tauopathy: a systems biology approach. Front Aging Neurosci. 6: 232.

Castro-Alvarez, J.F., A. Uribe-Arias, S.A., Cardona-Gomez, G.P. 2015. Cyclin-Dependent kinase 5 targeting prevents beta-Amyloid aggregation involving glycogen synthase kinase 3beta and phosphatases. J Neurosci Res. 93:1258-66.

CDC. 2008. http://www.cdc.gov/dhdsp/atlas/heart_stroke_atlas.

Chavez JC, Hurko O, Barone FC, Feuerstein GZ. 2009 Pharmacologic interventions for stroke: looking beyond the thrombolysis time window into the penumbra with biomarkers, not a stopwatch. Stroke. 40: e558-63.

Chen, C., Hu, Q., Yan, J., Yang, X., Shi, X., Lei, J., Chen, L., Huang, H., Han, J., Zhang, J.H., Zhou, C. 2009. Early inhibition of HIF-1alpha with small interfering RNA reduces ischemic-reperfused brain injury in rats. Neurobiol Dis. 33: 509-17.
Cheng, Y.D., Al-Khoury, L., Zivin, J.A. 2004. Neuroprotection for ischemic stroke: two decades of success and failure. NeuroRx. 1: 36-45.

CLINIGENE. European Network for the Advancement of Clinical Gene Transfer and Therapy. Available from: http://www. clinigene.eu/.

Choi, D.W., Rothman, S.M. 1990. The role of glutamate neurotoxicity in hypoxic-ischemic neuronal death. Annu Rev Neurosci. 13: 171-182.

Danielyan, L., Klein, R., Hanson, L.R., Buadze, M., Schwab, M,. Gleiter, C.H., Frey, W.H. 2010. Protective effects of intranasal losartan in the APP/PS1 transgenic mouse model of Alzheimer disease. Rejuvenation Res. 13: 195-201.

Demchuk, A.M., Buchan, A.M. 2000. Predictors of stroke outcome. Neurol Clin. 2000. 18: 455-73.

Dirnagl, U., Ladecola, C., Moskowitz, M.A. 1999. Pathobiology of ischaemic stroke: an integrated view. Trends Neurosci. 22: 391-397.

Dobkin, B.H., Dorsch, A. 2013. New evidence for therapies in stroke rehabilitation. Curr Atheroscler Rep. 15: 331.

Durukan, A.,Tatlisumak, T. 2007. Acute ischemic stroke: overview of major experimental rodent models, pathophysiology, and therapy of focal cerebral ischemia. Pharmacol Biochem Behav. 87: 179-197.

Drucker, E., Krapfenbauer, K. 2013. Pitfalls and limitations in translation from biomarker discovery to clinical utility in predictive and personalized medicine. The EPMA journa.l 4: 1-10.

Fillat, C. 2004. Perspectivas actuales de la terapia génica. BSCP Can Ped. 28: 203-207.

Fischer, A., Sananbenesi, F., Pang, P.T., Lu, B., Tsai, L.H. 2005. Opposing roles of transient and prolonged expression of p25 in synaptic plasticity and hippocampus-dependent memory. Neuron. 48: 825-38.

Fischer, P.M. 2001. Recent advances and new directions in the discovery and development of cyclin-dependent kinase inhibitors. Curr Opin Drug Discov Devel. 4: 623-34.

Fukuda A.M., Badaut, J. 2013. siRNA Treatment: “A Swordin-the-Stone” for Acute Brain Injuries. Genes (Basel). 4: 435-56.

Gemmell, E., Bosomworth, H., Allan, L., Hall, R., Khundakar, A., Oakley, A.E., Deramecourt, V., Polvikoski, T.M., O’Brien, J.T., Kalaria, R.N. 2012. Hippocampal neuronal atrophy and cognitive function in delayed poststroke and aging-related dementias. Stroke. 43: 808-14.

Gemmell, E., Tam, E., Allan, L., Hall, R., Khundakar, A., Oakley, A.E., Thomas, A., Deramecourt, V., Kalaria, R.N. 2014. Neuron volumes in hippocampal subfields in delayed poststroke and aging-related dementias. J Neuropathol Exp Neurol.73: 305-311.

Glicksman, M.A., Cuny GD, Liu M, Dobson B, Auerbach K, Stein RL, Kosik KS. 2007. New approaches to the discovery of cdk5 inhibitors. Curr Alzheimer Res. 4: 547-9.

Goldstein, L.B., Bushnell, C.D., Adams, R.J., Appel, L.J., Braun, L.T., Chaturvedi, S., Creager, M.A., Culebras, A., Eckel, R.H., Hart, R.G., Hinchey, J.A., Howard, V.J., Jauch, E.C., Levine, S.R., Meschia, J.F, Moore, W.S., Nixon, J.V., Pearson, T.A., American Heart Association Stroke Council., Council on Cardiovascular Nursing., Council on Epidemiology and Prevention., Council for High Blood Pressure Research., Council 
on Peripheral Vascular Disease., and Interdisciplinary Council on Quality of Care and Outcomes Research. 2011. Guidelines for the primary prevention of stroke: a guideline for healthcare professionals from the American Heart Association/American Stroke Association. Stroke. 42: 517-584.

Grimm, D., Kay, M.A. 2007. RNAi and gene therapy: a mutual attraction.Hematology Am Soc Hematol Educ Program. 473-81.

Gutiérrez-Vargas, J.A., Múnera, A., Cardona-Gómez, G.P. 2015. CDK5 knockdown prevents hippocampal degeneration and cognitive dysfunction produced by cerebral ischemia. $J$ Cereb Blood Flow Metab. 35: 1937-49.

Gutiérrez-Vargas, J.A., Moreno, H., Cardona-Gómez, G.P. 2016 Targeting CDK5 post-stroke provides long-term neuroprotection and rescues synaptic plasticity. J Cereb Blood Flow Metab. DOI: 10.1177/0271678X16662476

Gomez, D., Martinez, J.A., Hanson, L.R., Frey, W.H. 2nd, Toth, C.C. 2012. Intranasal treatment of neurodegenerative diseases and stroke. Front Biosci (Schol Ed). 4: 74-89.

Guan, J.S., Su SC, Gao J, Joseph N, Xie Z, Zhou Y, Durak O, Zhang L, Zhu JJ, Clauser KR, Carr SA, Tsai LH. 2011. Cdk5 is required for memory function and hippocampal plasticity via the cAMP signaling pathway. PLoS One, 2011. 6: e25735.

Halliday, G.M., McCann, H. 2010. The progression of pathology in Parkinson's disease. Ann N Y Acad Sci. 1184: 188-195.

Hawasli, A.H., Benavides, D.R., Nguyen, C., Kansy, J.W., Hayashi, K., Chambon, P., Greengard, P., Powell, C.M., Cooper, D.C., Bibb, J.A. 2007. Cyclin-dependent kinase 5 governs learning and synaptic plasticity via control of NMDAR degradation. Nat Neurosci. 10: 880-886.

Horn AI, F.S., Carvalho, S.M.R., Silvado, R.A.B., Babosa, P.M.K., Junior, A.D., Atallah, N.A., Fukujima, M.M., Prado, G.F. 2003. Cinesioterapia previne ombro doloroso em pacientes hemiplégicos/paréticos na fase sub-aguda do acidente vascular encefálico. Arq. Neuropsiquiatria. 61: 768-771.

Juliano, R.L., Dixit, V.R., Kang, H., Kim, T.Y., Miyamoto, Y., Xu, D. 2005. Epigenetic manipulation of gene expression: a tool kit for cell biologists. J Cell Biol. 169: 847-857.

Kay, M.A., Glorioso, J.C., Naldini, L. 2001. Viral vectors for gene therapy: the art of turning infectious agents into vehicles of therapeutics. Nat Med. 7: 33-40.

Kim, H.W., Cho, K.J., Lee, S.K., Kim, G.W. 2011. Apoptosis signal-regulating kinase 1 (Ask1) targeted small interfering RNA on ischemic neuronal cell death. Brain Res. 1412: 73-78.

Kim, I.D., Lim, C.M., Kim, J.B., Nam, H.Y., Nam, K., Kim, S.W., Park, J.S., Lee, J.K. 2010. Neuroprotection by biodegradable PAMAM ester (e-PAM-R)-mediated HMGB1 siRNA delivery in primary cortical cultures and in the postischemic brain. J Control Release. 142: 422-30.

Kim, I.D., Shin, J.H., Kim, S.W., Choi, S., Ahn, J., Han, P.L., Park, J.S., Lee, J.K. 2012. Intranasal delivery of HMGB1 siRNA confers target gene knockdown and robust neuroprotection in the postischemic brain. Mol Ther. 20: 829-39.

Kim, J.B., Sig Choi, J., Yu, Y.M., Nam, K., Piao, C.S., Kim, S.W., Lee, M.H., Han, P.L., Park, J.S., Lee, J.K. 2006. HMGB1, a novel cytokine-like mediator linking acute neuronal death and delayed neuroinflammation in the postischemic brain. J Neurosci. 26: 6413-21.
Kimura, T., Ishiguro, K., Hisanaga, S. 2014. Physiological and pathological phosphorylation of tau by Cdk5. Front Mol Neurosci. 7: 65.

Ko, J., Humbert S, Bronson RT, Takahashi S, Kulkarni AB, Li E, Tsai LH. 2001. p35 and p39 are essential for cyclindependent kinase 5 function during neurodevelopment. $J$ Neurosci. 21: 6758-6771.

Kusakawa, G., Saito, T., Onuki, R., Ishiguro, K., Kishimoto, T., Hisanaga, S. 2000. Calpain-dependent proteolytic cleavage of the p35 cyclin-dependent kinase 5 activator to p25. J Biol Chem. 275: 17166-17172.

Lavados, P.M., Hennis, A.J., Fernandes, J.G., Medina, M.T., Legetic, B., Hoppe, A., Sacks, C., Jadue, L., Salinas, R. 2007. Stroke epidemiology, prevention, and management strategies at a regional level: Latin America and the Caribbean. Lancet Neurol. 6: 362-72.

Lecca, D., Trincavelli, M.L., Gelosa, P., Sironi, L., Ciana, P., Fumagalli, M., Villa, G., Verderio, C., Grumelli, C., Guerrini, U., Tremoli, E., Rosa, P., Cuboni, S., Martini, C., Buffo, A., Cimino, M., Abbracchio, M.P. 2008. The recently identified P2Y-like receptor GPR17 is a sensor of brain damage and a new target for brain repair. PLoS One. 3: e3579.

Lo, E.H. 2008. A new penumbra: transitioning from injury into repair after stroke. Nat Med. 14: 497-500.

Lopes, J.P., Agostinho, P. 2011. Cdk5: multitasking between physiological and pathological conditions. Prog Neurobiol. 94: 49-63.

Markgraf, C.G., Velayo, N.L., Johnson, M.P., McCarty, D.R., Medhi, S., Koehl, J.R., Chmielewski, P.A., Linnik, M.D. 1998. Six-hour window of opportunity for calpain inhibition in focal cerebral ischemia in rats. Stroke. 29: 152-8.

Menn, B., Bach, S., Blevins, T.L., Campbell M, Meijer L, Timsit S. 2010. Delayed treatment with systemic (S)roscovitine provides neuroprotection and inhibits in vivo CDK5 activity increase in animal stroke models. PLoS One. 5: e12117.

Mitsios, N., Pennucci R, Krupinski J, Sanfeliu C, Gaffney J, Kumar P, Kumar S, Juan-Babot O, Slevin M. 2007. Expression of cyclin-dependent kinase 5 mRNA and protein in the human brain following acute ischemic stroke. Brain pathology. 17: 11-23.

Moskowitz, M.A., E.H. Lo, and C. Iadecola. 2010. The science of stroke: mechanisms in search of treatments. Neuron. 67: 181-198.

Moustafa, R.R. and J.C. Baron. 2008. Pathophysiology of ischaemic stroke: insights from imaging, and implications for therapy and drug discovery. Br J Pharmacol. 153 Suppl 1: S44-54.

Nys, G.M., van Zandvoort MJ, de Kort PL, Jansen BP, Kappelle LJ, de Haan EH. 2005. Restrictions of the Mini-Mental State Examination in acute stroke. Arch Clin Neuropsychol. 20: $623-9$.

OMS. 2016. Discapacidades.

Ohshima, T., Ogura H, Tomizawa K, Hayashi K, Suzuki H, Saito T, Kamei H, Nishi A, Bibb JA, Hisanaga S, Matsui H, Mikoshiba K. 2005. Impairment of hippocampal longterm depression and defective spatial learning and memory in p35 mice. J Neurochem. 94: 917-925.

Patrick, G.N., Zhou P, Kwon YT, Howley PM, Tsai LH. 1998. p35, the neuronal-specific activator of cyclin-dependent kinase 5 (Cdk5) is degraded by the ubiquitin-proteasome pathway. J Biol Chem. 273: 24057-2464. 
Patrick, G.N., Zukerberg, L., Nikolic, M., De la Monte, S., Dikkes, P., Tsai, L.H. 1999. Conversion of p35 to p25 deregulates $\mathrm{Cdk} 5$ activity and promotes neurodegeneration. Nature. 402: 615-622.

Parker, J.S., Roe, S.M., Barford, D. 2004. Crystal structure of a PIWI protein suggests mechanisms for siRNA recognition and slicer activity. EMBO J. 23: 4727-37.

Piedrahita, D., Hernández, I., López-Tobón, A., Fedorov, D., Obara, B., Manjunath, B.S., Boudreau, R.L., Davidson, B., Laferla, F., Gallego-Gómez, J.C., Kosik, K.S., Cardona-Gómez, G.P. 2010. Silencing of CDK5 reduces neurofibrillary tangles in transgenic Alzheimer's mice. $J$ Neurosci. 30: 13966-13976.

Pluta, R., Jolkkonen, J., Cuzzocrea, S., Pedata, F., Cechetto, D., Popa-Wagner, A. 2011. Cognitive impairment with vascular impairment and degeneration. Cognitive impairment with vascular impairment and degeneration. Curr Neurovasc Res. 8: 342-350.

Posada-Duque, R.A., Barreto, G.E., Cardona-Gomez, G.P. 2014. Protection after stroke: cellular effectors of neurovascular unit integrity. Front Cell Neurosci. 8: 231.

Posada-Duque, R.A., López-Tobón, A., Piedrahita, D., GonzálezBillault, C., Cardona-Gomez, G.P. 2015. p35 and Rac1 underlie the neuroprotection and cognitive improvement induced by CDK5 silencing. J Neurochem. 134: 354-370.

Posada-Duque, R.A., Ramirez, O., Härtel, S., Inestrosa, N.C., Bodaleo, F., González-Billault, C., Kirkwood, A., Cardona-Gómez, G.P. 2017. CDK5 downregulation enhances synaptic plasticity. Cell Mol Life Sci. 74: 153-172.

Price, M., Badaut, J., Thevenet, J., Hirt, L. 2010. Activation of c-Jun in the nuclei of neurons of the CA-1 in thrombin preconditioning occurs via PAR-1. J Neurosci Res. 88: 1338-1347.

Razzak, J., Kellermann, A. 2002. Emergency medical care in developing countries is it worthwhile? Bulletin of the World Health Organization. 80: 900-905.

Renner, D.B., Frey, 2nd, and L.R. Hanson. 2012. Intranasal delivery of siRNA to the olfactory bulbs of mice via the olfactory nerve pathway. Neurosci Lett. 513: 193-7.

Sapru, M.K., Yates, J.W., Hogan, S., Jiang, L., Halter, J., Bohn, M.C. 2006. Silencing of human alpha-synuclein in vitro and in rat brain using lentiviral-mediated RNAi. Exp Neurol. 198: 382-90.

Slevin M, Krupinski J. 2009. Cyclin-dependent kinase-5 targeting for ischaemic stroke. Curr Opin Pharmacol. 9: 119-24.

Sun, J.H., Tan, L., Yu, J.T. 2014. Post-stroke cognitive impairment: epidemiology, mechanisms and management. Ann Transl Med. 2: 80.

Szabo, K., Szabo, K., Förster, A., Jäger, T., Kern, R., Griebe, M., Hennerici, M.G., Gass, A. 2009. Hippocampal lesion patterns in acute posterior cerebral artery stroke: clinical and MRI findings. Stroke. 40: 2042-2045.

Tan, X., Chen, Y., Li, J., Li, X., Miao, Z., Xin, N., Zhu, J., Ge, W., Feng, Y., Xu, X. 2015. The inhibition of Cdk5 activity after hypoxia/ischemia injury reduces infarct size and promotes functional recovery in neonatal rats. Neuroscience. 290: 552-60.
Thorne, R.G., Hanson, L.R., Ross, T.M., Tung, D., Frey, W.H. 2nd. 2008. Delivery of interferon-beta to the monkey nervous system following intranasal administration. Neuroscience. 152: 785-97.

Thorne, R.G., Pronk, G.J., Padmanabhan, V., Frey, W.H. 2nd. 2004. Delivery of insulin-like growth factor-I to the rat brain and spinal cord along olfactory and trigeminal pathways following intranasal administration. Neuroscience. 127: 481-496.

Thorne, R.G., Frey, W.H. $\mathbf{2}^{\text {nd }}$. 2001. Delivery of neurotrophic factors to the central nervous system: pharmacokinetic considerations. Clin Pharmacokinet. 40: 907-946.

Tsai, L.H., Takahashi, T., Caviness, V.S. Jr, Harlow, E. 1993. Activity and expression pattern of cyclin-dependent kinase 5 in the embryonic mouse nervous system. Development. 119: $1029-40$.

Uribe-Arias, A., Posada-Duque, R.A., González-Billault, C., Villegas, A., Lopera, F., Cardona-Gómez, G.P. 2016. p120-catenin is necessary for neuroprotection induced by CDK 5 silencing in models of Alzheimer's disease. $J$ Neurochem. 138: 624-39.

Vautrin, J., Barker, J.L. 2003. Presynaptic quantal plasticity: Katz's original hypothesis revisited. Synapse. 47: 184-199.

Wen, Y., Yang, S.H., Liu, R., Perez, E.J., Brun-Zinkernagel, A.M., Koulen, P., Simpkins, J.W. 2007. Cdk5 is involved in NFT-like tauopathy induced by transient cerebral ischemia in female rats. Biochimica et biophysica acta. 1772: 473-483.

WHO. 2015. http://www.who.int/mediacentre/factsheets/fs362/en/.

Won, S.J., Kim, D.Y., Gwag, B.J. 2002. Cellular and molecular pathways of ischemic neuronal death. J Biochem Mol Biol. 35: 67-86.

Zhang, S., Edelmann, L., Liu, J., Crandall, J.E., Morabito, M.A. 2008. Cdk5 regulates the phosphorylation of tyrosine 1472 NR2B and the surface expression of NMDA receptors. J Neurosci. 28: 415-424.

Zhang, L., Z.G. Zhang, Chopp, M. 2012 The neurovascular unit and combination treatment strategies for stroke. Trends Pharmacol Sci. 33: 415-22.

Zhao, B., Zhao, C.Z., Zhang, X.Y., Huang, X.Q., Shi, W.Z., Fang, S.H., Lu, Y.B., Zhang, W.P., Xia, Q. 2012. The new P2Y-like receptor $G$ protein-coupled receptor 17 mediates acute neuronal injury and late microgliosis after focal cerebral ischemia in rats. Neuroscience. 202: 42-57.

Zheng, Y.Q., Liu, J.X., Li, X.Z., Xu, L., Xu, Y.G. 2009. RNA interference-mediated downregulation of Beclin1 attenuates cerebral ischemic injury in rats. Acta Pharmacol Sin. 30: 919-27.

Zheng, M., Leung, C.L., Liem, R.K. 1998. Region-specific expression of cyclin-dependent kinase 5 (cdk5) and its activators, p35 and p39, in the developing and adult rat central nervous system. J Neurobiol. 35: 141-159. 